\title{
Styrene-diene Block-copolymers Reinforced with Polystyrene
}

\author{
PAUL GHIOCA, RAMONA MARINA GRIGORESCU*, LORENA IANCU, BOGDAN SPURCACIU, CRISTIAN ANDI NICOLAE, \\ AUGUSTA RALUCA GABOR \\ National Institute for Research \& Development in Chemistry and Petrochemistry - ICECHIM, 202 Spl. Independentei, 060021, \\ Bucharest, Romania
}

The paper presents the polystyrene reinforcing effect of some styrene-diene block-copolymers on the physical-mechanical characteristics and thermal degradation stability of the associated composites.

\begin{abstract}
Keywords: styrene-diene block-copolymers, polystyrene, reinforcing effect, thermal degradation, mechanical properties
\end{abstract}

The use of polymers in more and more areas of industrial production has led to an increasing need for diversifying their physical-mechanical characteristics in order to ensure the properties required by various applications. It was proved that an easier technical and economical method to diversify these properties is the melt compounding of polymers, usually during their processing [1-4].

The styrene-diene block-copolymers with majority diene composition present vulcanized elastomer properties at ambienttemperature due to the segregation of polystyrene blocks as dispersed domains into the diene phase, thus ensuring the physical crosslinking of the polydiene. At temperatures above the polystyrene glass transition temperature $\left(T_{0}\right)$, the block-copolymers exhibit plastic behavior and thus can be melt processed with other thermoplastic polymers with different characteristics, providing a material with a wide range of physicalmechanical properties corresponding with the requirements of various applications $[5,6]$.

Modifying the styrene-diene block-copolymers with polystyrene (PSt) leads to the obtaining of composites with improved processability due to a reduced material melt viscosity simultaneously with an increase in hardness, toughness and dielectric constant. These characteristics allow the composite to be used as insulating material in electric cables production [6-8].

This paper presents the polystyrene reinforcing effect on some styrene-butadiene and styrene-isoprene blockcopolymers with a content of about $30 \%$ styrene.

\section{Experimental part}

The reinforcement study with polystyrene was performed using a star styrene-butadiene-styrene (SBS) and a linear styrene-isoprene-styrene (SIS) blockcopolymers synthetized by sequential anionic polymerization of monomers in cyclohexane solution, the reaction being initiated with n-butyl lithium [9-11]. After their synthesis, the block-copolymers were stabilized with $1 \%$ 2, 6-di-tert-butyl-4-methylphenol (TOPANOL OC) directly in the polymerization cyclohexane solution.

The block-copolymers were separated from the solution by stripping with hot water and water vapor; finally the polymers were dried in an oven at $60^{\circ} \mathrm{C}$ under reduced pressure.

By gel permeation chromatography (GPC) the molecular masses of the polymers and the component blocks collected during different synthesis phases were established. The physical-mechanical properties were determined on sheets with a thickness of about $1 \mathrm{~mm}$ obtained by centrifugal casting at maximum $60^{\circ} \mathrm{C}$ from the toluene solution, in accordance with standardized requirements for styrene-diene block-copolymers characterization.

The properties of styrene-diene block-copolymers are presented in table 1.

BASF polystyrene (Polystyrol 143) used as reinforcing agent in this paper presented the following properties:

- Tensile strength : $48 \mathrm{MPa}$

- Elongation at break : $2.2 \%$

- Izod impact strength: $3.1 \mathrm{KJ} / \mathrm{m}^{2}$ $\min$.

- Melt mass flow rate at $190^{\circ} \mathrm{C}$, load of $5 \mathrm{~kg}: 3.1 \mathrm{~g} / 10$

The composites were achieved by polystyrene dosing into the $20 \%$ toluene solution under stirring until the complete dissolution.

Using of toluene as solvent is indicated by literature [1214] because it is a non-selective solvent for polystyrene and polybutadiene, respectively polyisoprene blocks thus avoiding the morphological changes in the biphasic structure of styrene-diene block-copolymers that could perturb the correct interpretation of the reinforcing effect.

The polystyrene was dosed in steps of $5 \%$ until $30 \%$, the maximum limit being imposed to maintain the continuous polydiene phase in which polystyrene was dispersed as reinforcing agent [ 7].

The composites of styrene-diene block-copolymers modified with polystyrene were obtained by dissolving the blends solutions by centrifugal casting [15, 17]. The solvent was complete removed in a vacuum oven at $60^{\circ} \mathrm{C}$.

The composites tensile properties were determined on stamped specimens from the obtained sheets with a 0.8$1 \mathrm{~mm}$ thickness, using a FPZ 100 dynamometer, with an elongation rate of $500 \mathrm{~mm} / \mathrm{min}$, according to SR EN ISO 527-96.

Differential Scanning Calorimetry (DSC) determinations were carried out with a Q2000 DSC (TA Instruments) assisted by a Liquid Nitrogen Cooling System (LNCS), in the temperature range room temperature $(\mathrm{RT}) \sim+150^{\circ} \mathrm{C}$, using aluminum pans and helium (99.999\%) as purge gas at a flow rate of $30 \mathrm{~mL} / \mathrm{min}$. Method: 1 : Ramp $40^{\circ} \mathrm{C} / \mathrm{min}$ from RT to $150^{\circ} \mathrm{C}$; 2: Isothermal for $2 \mathrm{~min}$; 3 : Ramp $40^{\circ} \mathrm{C} /$ min from $150^{\circ} \mathrm{C}$ to RT; 4: Isothermal for 2 min; 5: Ramp $20^{\circ} \mathrm{C} / \mathrm{min}$ from RT to $150^{\circ} \mathrm{C}$.

Dynamic mechanical properties of elastomer composites were determined on a Q 800 Dynamic Mechanical Analyzer (TA Instruments) using the Universal 


\begin{tabular}{|c|c|c|c|}
\hline $\begin{array}{c}\text { Crt. } \\
\text { no. }\end{array}$ & Property & SBS & SIS \\
\hline 1. & Polystyrene content, $\%$ & 32.4 & 30.2 \\
\hline 2. & Total molecular mass, $\mathrm{g} /$ mole & 177400 & 116800 \\
\hline 3. & Polystyrene block molecular mass, g/mole & 14400 & 17600 \\
\hline 4. & Polybutadiene block molecular mass, g/mole & 119800 & - \\
\hline 5. & Polyisoprene block molecular mass, g/mole & - & 81600 \\
\hline 6. & Yield, $\mathrm{MPa}$ & 5.4 & - \\
\hline 7. & Elongation modulus at $300 \%, \mathrm{MPa}$ & 4.1 & 2.7 \\
\hline 8. & Tensile strength, $\mathrm{MPa}$ & 23.5 & 14.2 \\
\hline 9. & Elongation at break, $\%$ & 840 & 1430 \\
\hline 10. & Remanent elongation, $\%$ & 7 & 12 \\
\hline 11. & Hardness, Sh A & 67 & 48 \\
\hline
\end{tabular}

Table 1

PHYSICO MECHANICAL PROPERTIES OF STYRENE-DIENE BLOCKCOPOLYMERS
Analysis 2000 software for processing of the results. The obtained sheets with dimensions $10 \times 10 \mathrm{~mm}$ (length $\mathrm{x}$ width) were cut by two using a perforating punches according to the apparatus instructions and the working method. The determinations were carried out from room temperature to $165^{\circ} \mathrm{C}$, with a heating rate of $3^{\circ} \mathrm{C} / \mathrm{min}$, amplitude of $15 \mu \mathrm{m}$, frequency of $1 \mathrm{~Hz}$, using the shear sandwich clamp.

Thermogravimetric analysis (TGA) was carried out with a Q5000IR TGA (TA Instruments) in the temperature range: RT (room temperature) $\sim+700{ }^{\circ} \mathrm{C}$, using platinum pans and nitrogen (99.999\%) as purge gas at a flow rate of 50 $\mathrm{mL} / \mathrm{min}$. Method: 1 : Ramp $10^{\circ} \mathrm{C} / \mathrm{min}$ from RT to $700^{\circ} \mathrm{C} ; 2$ : Select gas 2 (Synthetic Air, 99.999\%); 3: Isothermal for 5 $\min$.

The materials hardness was determined on a Shore A durometer.

\section{Results and discussions}

According to the SAXS, TEM and SANS morphological studies performed on blends films obtained from styrenediene block-copolymers and polystyrene with different molecular masses solutions established that PSt with similar or lower molecular mass than the elastomers component blocks enters into the polystyrene elastomeric blocks [17-19].

The polystyrene with a higher molecular mass than that of PSt blocks from the block-copolymers forms separated domains dispersed into the elastomer continuous phase [17, 20-22].

The morphological studies performed on polystyrene composites obtained by melt alloying with other incompatible polymers proved that the polystyrene as minor component of compounds is aleatory distributed into the continuous phase of the major component as domains with irregular forms. This morphology does not allow the achieving of composites with performant physical-mechanical properties [23].

In the case of styrene-diene block-copolymers reinforced with polystyrene obtained by centrifugal casting method from toluene solution, the solvent evaporation is carried out in a relative long time (3-4 h) allowing PSt separation as domains with regular forms, uniform dispersed into the elastomer continuous phase $[17,20]$. In this case it is expected that the physical-mechanical characteristics will present more performant values compared with the composites obtained by melt processing.

The polystyrene presence in the polybutadiene matrix leads even from the first dosage (5\%) to the interphase reducing surrounding the polystyrene domains from the block-copolymer, the phenomenon being highlighted by a Yield sharp decrease, as can be seen in figure 1 .

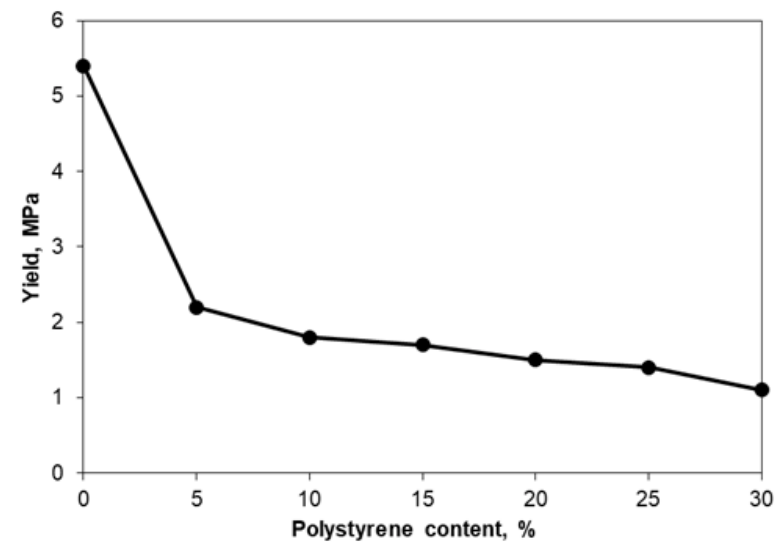

Fig. 1. Yield variation depending on the polystyrene dosage from SBS composites

Increasing the PSt dosage leads to a slow decrease of composites Yield, but not to its complete disappearance indicating the maintaining of incomplete separation of the polymeric phases.

The styrene-isoprene-styrene block-copolymer and its composites do not present Yield (table 1) demonstrating a higher separation degree of polystyrene phase from polyisoprene one due to a higher incompatibility of these polymers [23].

The different separation degree of polymer phases in the case of these two block-copolymers is also evidenced by the different polystyrene glass transition temperatures values determined by DMA and DSC measurements. In figure 2 can be observed the lower values of polystyrene 


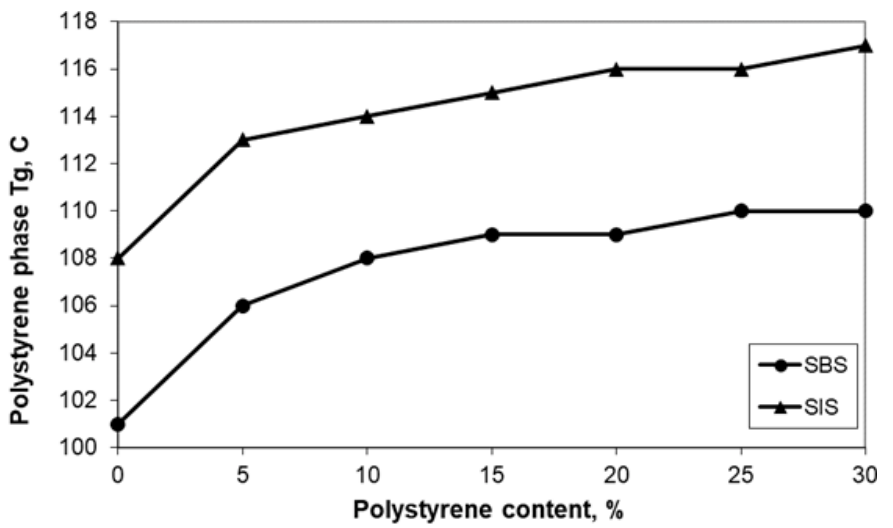

Fig. 2. The variation of the glass transition temperature depending on the polystyrene dosage from SBS and SIS composites

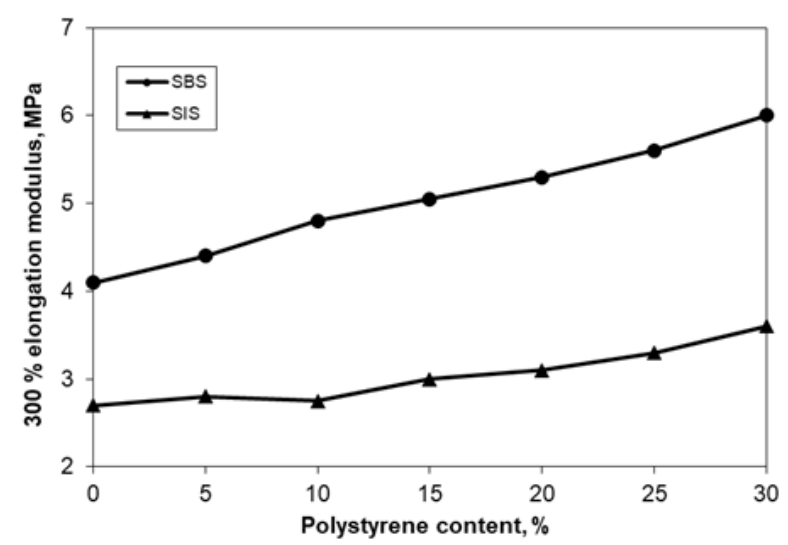

Fig. 3 The variation of the $300 \%$ elongation modulus depending on the polystyrene dosage from SBS and SIS composites

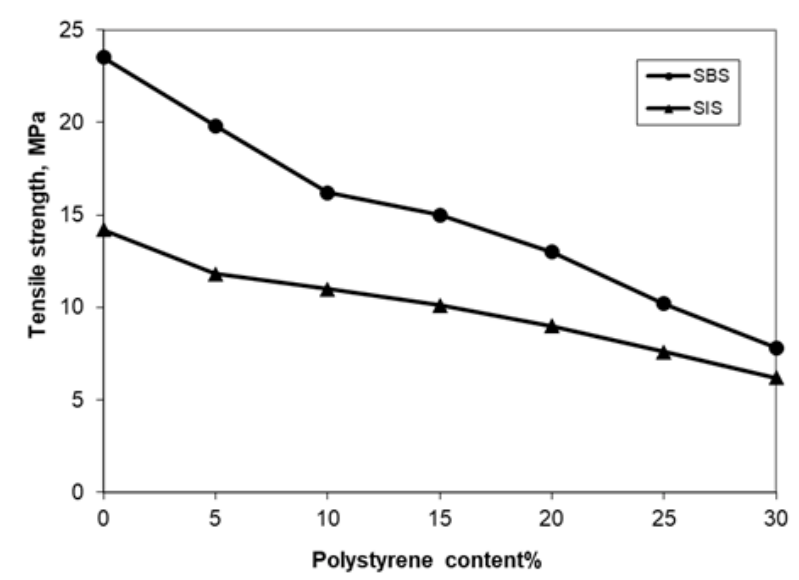

Fig. 4. Tensile strength variation depending on the polystyrene dosage from SBS and SIS composites

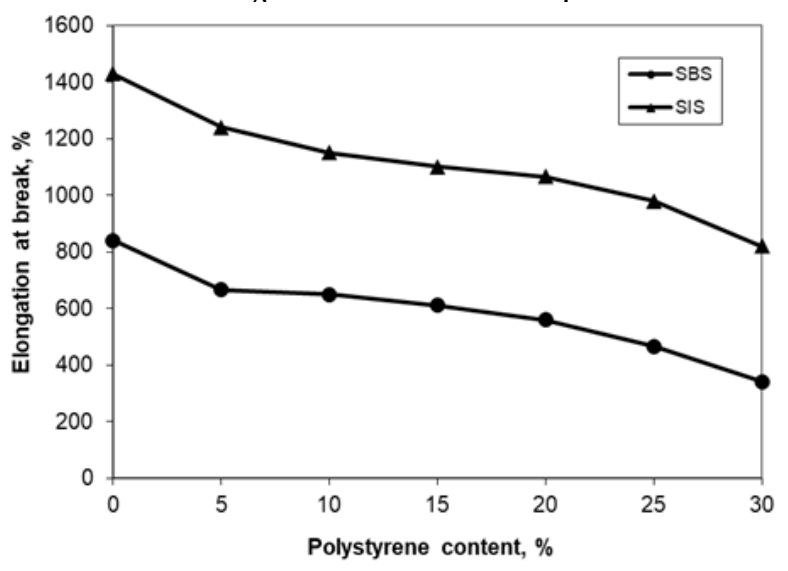

Fig. 5. Elongation at break variation depending on the polystyrene dosage from SBS and SIS composites

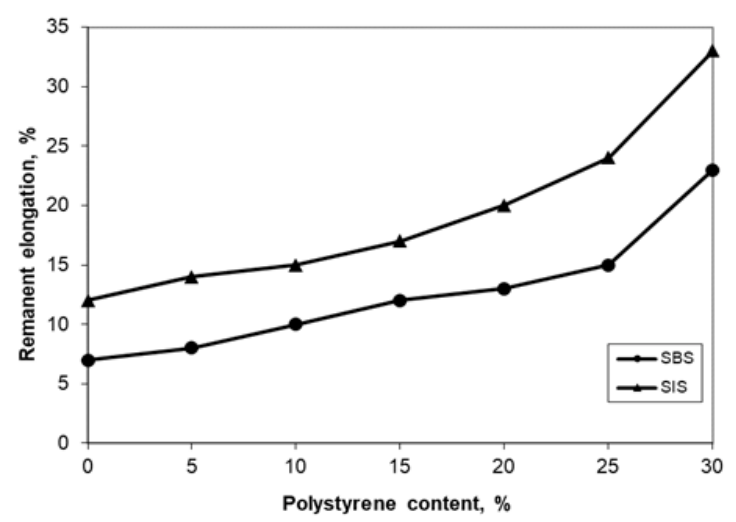

Fig. 6. Remanent elongation variation depending on the polystyrene dosage from SBS and SIS composites

phase Tg from SBS compared to SIS confirming the different separation degree discussed above.

The polystyrene used as reinforcing agent has a higher molecular mass than the component blocks from the block-copolymers and consequently presents a higher Tg than the elastomers. Increasing PSt weight in composites led to an overall increase of polystyrene phase $\mathrm{Tg}$ of composites.

Incorporation of polystyrene into the block-copolymers polydiene phase reduces the inter-chain contact and the reinforcing effect is more and more pronounced in a direct correlation with the increasing the PSt dosage in the composite material leading to a higher value of the 300\% elongation modulus (fig. 3), decreasing the tensile strength (fig. 4) and the elongation at break (fig. 5) and increasing the remanent elongation (fig. 6).

It should be noted the slower decrease of the tensile strength determined for SIS composites in contrast with SBS ones (fig. 4) across the PSt dosage' domain indicating a greater cohesion between the component phases of these composites as a consequence of a higher interphase adhesion between polystyrene and polyisoprene compared to the polystyrene-polybutadiene one.

The change in the elastic behavior of styrene-diene blockcopolymers produced by PSt reinforcing is also highlighted by the storage modulus variation (DMA) depending on the filler dosage (figs. 7 and 8).

In the case of SBS composites it is noticed a decrease of the storage modulus at smaller polystyrene dosages, indicating a material elastification in contradiction at first sight, with the stiffening effect expected to be produced by the filler.

This initial elastification of the composite is a consequence of the change in SBS block-copolymers morphology, the first polystyrene dosages leading to a Yield drastic reduction, as mentioned before (fig. 1). The disappearance of PSt bonds between the polymeric

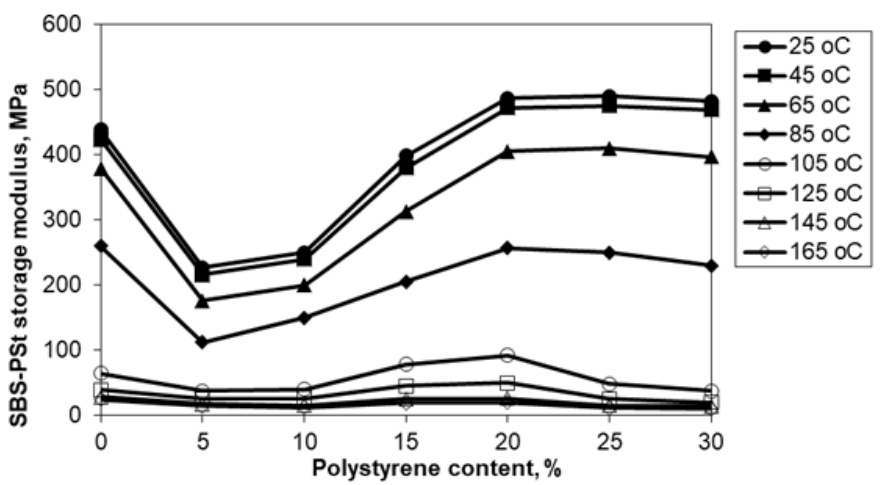

Fig. 7. Storage modulus variation for SBS composites depending on the polystyrene dosage 


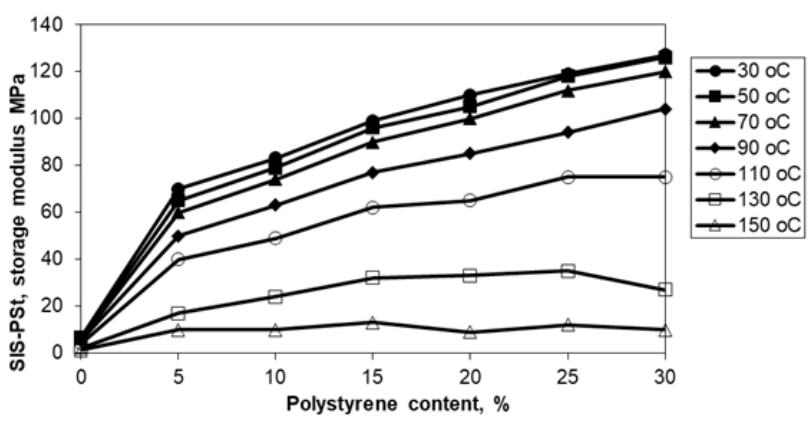

Fig. 8. Storage modulus variation of SIS composites depending on the polystyrene dosage

domains improves the elastification and, in this case, the effort for elastic deformation evidenced by the storage modulus presents an important increase as can be seen in figure 7.

Further increase of polystyrene dosage in SBS blockcopolymers composites enhances the reinforcement due to the mobility decrease of polybutadiene chains [24-26] and the phenomenon is evidenced by higher values of the storage modulus.

SIS block-copolymer does not have Yield (table 1) thus the polystyrene reinforcement effect leads to a stiffer composite highlighted by a continuous increase of the storage modulus, more accentuated at the filler first dosages (fig. 8).

The higher values of the storage modulus for SBS blockcopolymers composites are due to the greater molecular mass of polybutadiene chains and the superior entanglement degree of this phase compared to SIS polyisoprene chains.

Itcan be observed the drastically decrease of the storage modulus for both block-copolymers composites at temperatures about polystyrene vitreous transition throughout the reinforcing field. This composites behavior is due to the polystyrene domains melt that leads to the disappearance of physical crosslinking thus the composite material loses its elasticity becoming a viscous fluid as a whole.

The viscous behavior of block-copolymers composites is characterized by the loss modulus variation depending on the reinforcing degree with polystyrene and it can be observed in figures 9 and 10 .

In the case of SBS block-copolymers the Yield significant reduction at the first polystyrene dosages indicates a morphological change (the disappearance of polystyrene bonds between the domains) resulting in improving the elastomer phase mobility under stress and consequently to a decrease of composites viscosity, a phenomenon evidenced by the loss modulus decrease (fig. 9).

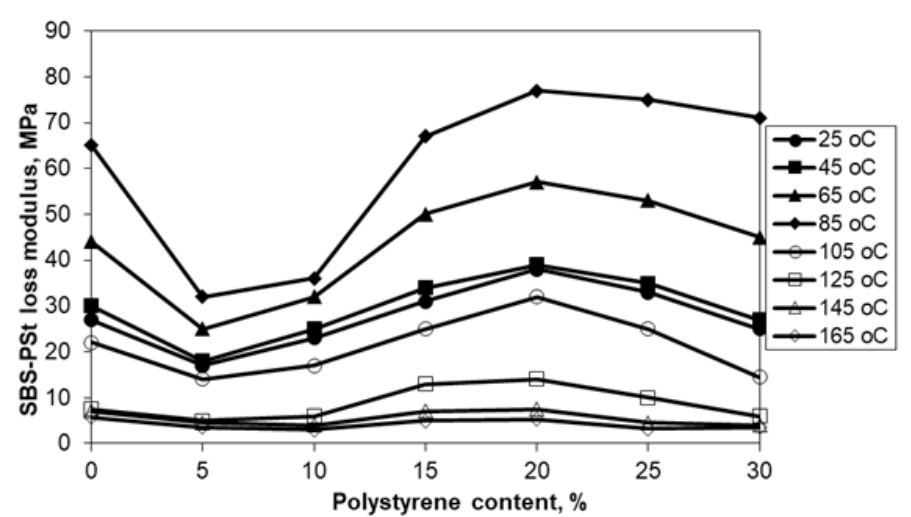

Fig. 9. Loss modulus variation for SBS composites depending on the polystyrene dosage

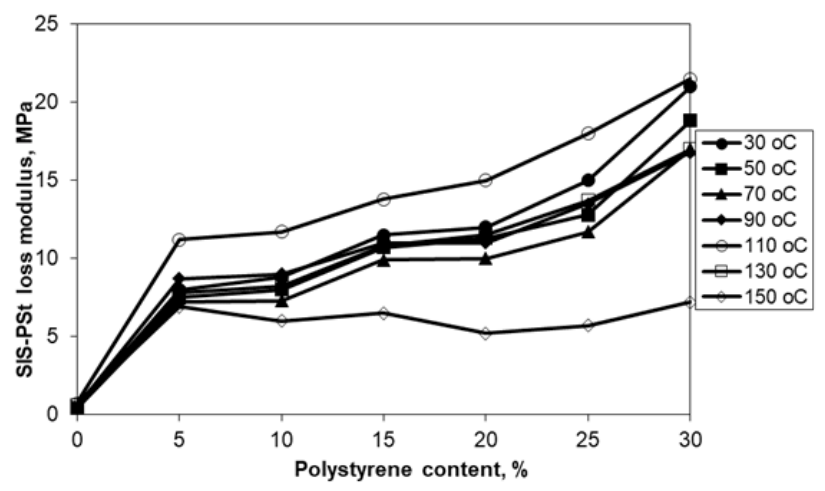

Fig. 10. Loss modulus variation for SIS composites depending on the polystyrene dosage

Further increase of polystyrene dosage leads to higher values of the loss modulus due to the composite reinforcement.

Yield absence in SIS block-copolymers enables the elastomer reinforcing from the first polystyrene dosage, the composites viscosity being continuously increased as can be seen from the higher values of the loss modulus (fig. 10).

The composites viscosity (loss modulus) of both blockcopolymers decreases as the temperature increases until reaching polystyrene phase $\mathrm{Tg}$ when the composite softens and the viscosity presents a significant increase. At temperatures higher than polystyrene $\mathrm{Tg}$ the viscosity decreases sharply due to the pronounced fluidity of polystyrene blocks.

The higher loss modulus values for SBS blockcopolymers composites are due to the superior molecular mass and to a stronger entanglement of polybutadiene chains as for the storage modulus.

The hardness of SBS and SIS composites increases relatively uniform with the polystyrene weight in the system following the simple charging rule of an elastic material with a harder one and no significant influence of elastomeric block nature on this property is observed according to figure 11 .

The thermal degradation behavior of composites and component polymers are summarized in tables 2 and 3 .

The polymers and their composites were stabilized with $1 \%$ 2, 6-di-tert-butyl-4-methylphenol (TOPANOL OC) providing protection against thermal degradation until a temperature of about $200^{\circ} \mathrm{C}$, the loss weight in this domain being below $1 \%$ according to tables 2 and 3. TOPANOL OC has a boiling temperature of $172^{\circ} \mathrm{C}$ so at higher temperatures it is volatilized and cannot stabilize the composites at thermal degradation.

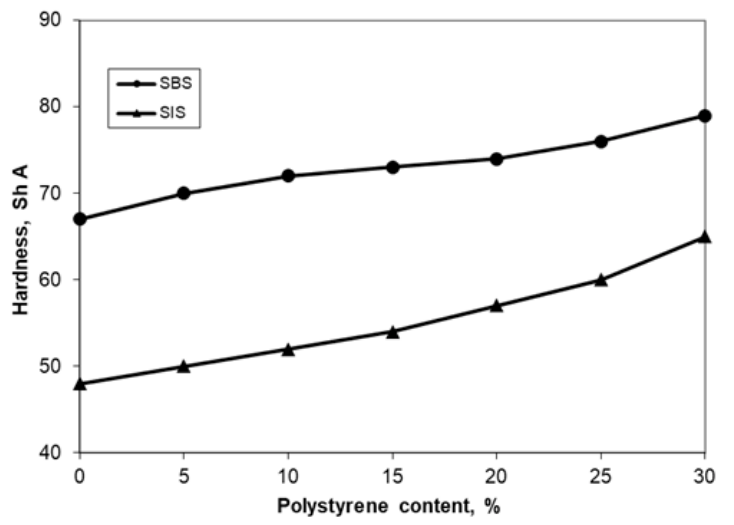

Fig. 11. Hardness variation depending on the polystyrene dosage 
Table 2

THERMAL DEGRADATION BEHAVIOR OF SBS-PSt COMPOSITES

\begin{tabular}{|c|c|c|c|c|c|c|c|c|c|c|c|c|c|}
\hline \multirow{2}{*}{$\begin{array}{c}\text { PSt } \\
\text { content }\end{array}$} & \multirow{2}{*}{$\begin{array}{c}\begin{array}{c}\text { RT- } \\
150^{\circ} \mathrm{C}\end{array} \\
\text { Wt. } \\
\text { loss }\end{array}$} & \multirow{2}{*}{ 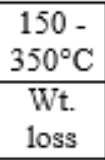 } & \multicolumn{2}{|c|}{$350-390^{\circ} \mathrm{C}$} & \multicolumn{2}{|c|}{$390-444^{\circ} \mathrm{C}$} & \multicolumn{2}{|c|}{$444-457^{\circ} \mathrm{C}$} & \multicolumn{2}{|c|}{$457-700^{\circ} \mathrm{C}$} & \multirow{2}{*}{$\begin{array}{c}\text { Residue } \\
700^{\circ} \mathrm{C}\end{array}$} & \multicolumn{2}{|c|}{ Onset } \\
\hline & & & $\begin{array}{l}\text { Wt. } \\
\text { loss }\end{array}$ & $T \max$ & $\begin{array}{l}\text { Wt. } \\
\text { loss }\end{array}$ & $T \max$ & Wt. loss & $T \max$ & $\begin{array}{l}\text { Wt. } \\
\text { loss }\end{array}$ & $T \max$ & & Weight & Temp \\
\hline$(\%)$ & $\%$ & $\%$ & $\%$ & ${ }^{\circ} \mathrm{C}$ & $\%$ & ${ }^{\circ} \mathrm{C}$ & $\%$ & ${ }^{\circ} \mathrm{C}$ & $\%$ & 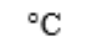 & 70 & $\%$ & ${ }^{\circ} \mathrm{C}$ \\
\hline 0 & 0.06 & 0.96 & 6.23 & 372.6 & 38.88 & 435.4 & 21.31 & 452.3 & 32.35 & 468.1 & 0.22 & 99.92 & 403.7 \\
\hline 5 & 0.08 & 1.05 & 5.57 & 371.6 & 39.00 & 432.0 & 21.90 & 452.2 & 32.15 & 468.4 & 0.27 & 99.86 & 403.9 \\
\hline 10 & 0.09 & 1.41 & 5.92 & 373.3 & 41.21 & 43 & 1.16 & 4 & 30.00 & 40 & 0.21 & 99.71 & 404.0 \\
\hline 15 & 0.14 & 1.59 & 5.19 & 374.8 & 42.85 & 430.6 & 21.45 & 451.7 & 28.50 & 467.4 & 0.24 & 99.43 & 404.6 \\
\hline 20 & 0.17 & 1.75 & 4.89 & 374.9 & 49.31 & 435.0 & 19.26 & 450.0 & 24.30 & 467.5 & 0.33 & 99.33 & 406.2 \\
\hline 25 & 0.33 & 2.54 & 4.99 & 380.9 & 53.72 & 430.7 & 20.76 & 449.6 & 17.46 & 466.4 & 0.2 & 98.60 & 403.5 \\
\hline 30 & 0.24 & 2.74 & 5.00 & 369.4 & 53.36 & 426.4 & 16.50 & 449.9 & 21.94 & 467.7 & 0.22 & 99.14 & 400.2 \\
\hline 100 & 0.01 & 4.69 & 11.72 & 368.9 & 83.33 & 414.8 & 0.17 & & 0.04 & & 0.04 & 97.58 & 393.2 \\
\hline
\end{tabular}

Table 3

THERMAL DEGRADATION BEHAVIOR OF SIS-PST COMPOSITE

\begin{tabular}{|c|c|c|c|c|c|c|c|c|}
\hline \multirow{2}{*}{ PSt content } & RT-200 & \multicolumn{2}{|c|}{$200-403.3^{\circ} \mathrm{C}$} & \multicolumn{2}{|c|}{$403.3-550^{\circ} \mathrm{C}$} & Residue & \multicolumn{2}{|c|}{ Onset } \\
\cline { 2 - 9 } & Wt. loss & Wt. loss & Tmax & Wt. loss & Tmax & $700^{\circ} \mathrm{C}$ & Weight & Temp \\
\hline$(\%)$ & $\%$ & $\%$ & ${ }^{\circ} \mathrm{C}$ & $\%$ & ${ }^{\circ} \mathrm{C}$ & $\%$ & $\%$ & ${ }^{\circ} \mathrm{C}$ \\
\hline 0 & 0.23 & 67.16 & 375.3 & 32.13 & 423.6 & 0.43 & 99.59 & 351.1 \\
\hline 5 & 0.17 & 65.27 & 375.5 & 34.16 & 425.0 & 0.36 & 99.60 & 350.8 \\
\hline 10 & 0.42 & 63.26 & 375.1 & 35.84 & 423.9 & 0.40 & 99.18 & 351.0 \\
\hline 15 & 0.32 & 60.74 & 375.8 & 38.51 & 425.8 & 0.35 & 99.19 & 350.9 \\
\hline 20 & 0.43 & 56.45 & 376.7 & 42.79 & 426.6 & 0.27 & 98.90 & 351.4 \\
\hline 25 & 0.59 & 55.78 & 376.4 & 43.37 & 424.9 & 0.19 & 98.63 & 350.3 \\
\hline 30 & 0.78 & 54.06 & 374.9 & 44.86 & 424.0 & 0.21 & 98,30 & 350.9 \\
\hline 100 & 0.23 & 35.52 & & 64.20 & 414.8 & 0.04 & 97.58 & 353.2 \\
\hline
\end{tabular}

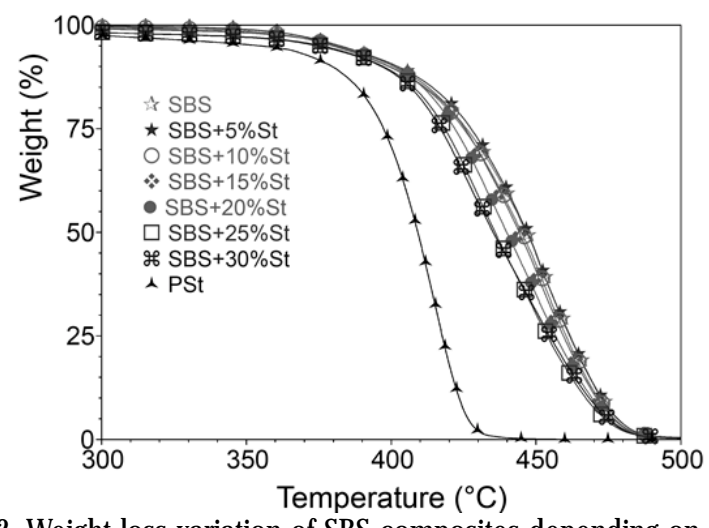

Fig. 12. Weight loss variation of SBS composites depending on the polystyrene dosage

In the range $150-350^{\circ} \mathrm{C}$ the weight losses of SBS blockcopolymers and their composites are lower, under 3\%, because the polybutadiene chains in the first degradation step are randomly cleaving and the formed macro-radicals are stabilized by cyclization and crosslinking [27-30]. The weight loss in the range of $350-390^{\circ} \mathrm{C}$ are still small, of about $5 \%$, and are due to polystyrene degradation by randomly cleavage in the first stage and then by depolymerization [27, 31].

It should be noted the independent degradation of polybutadiene chains and polystyrene blocks with no significant interference in the two degradation mechanisms [27].

In the range of $390-444^{\circ} \mathrm{C}$ the most advanced breakdown of SBS block-copolymers composites occurs, the weight losses increasing from $39 \%$ to $53 \%$ with

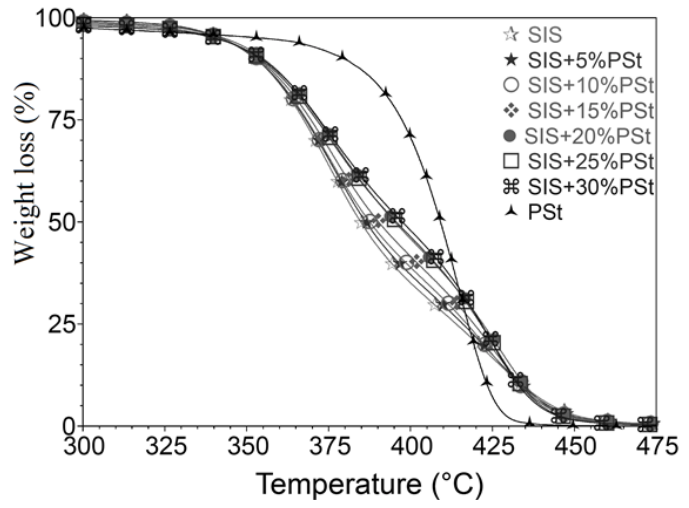

Fig. 13. Weight loss variation of SIS composites depending on the polystyrene dosage

polystyrene dosage in the system because of its strong depolymerization.

The degradation process continues in the range of 444$457^{\circ} \mathrm{C}$ with a practically the same (about $20 \%$ ) weight loss for all composites demonstrating the chain destruction by advanced cleavage with no transfer or cyclization reactions.

Practically total (more than 99\%) pyrolysis of SBS blockcopolymers and of polystyrene composites occurs between $457-700{ }^{\circ} \mathrm{C}$.

SIS block-copolymers and composites exhibit a weight loss of over $55 \%$ in the temperature range of $200-403^{\circ} \mathrm{C}$ (table 3 ) indicating an advanced material destruction mostly by polyisoprene chain cleavage [34, 35]. The weight loss decreases as the polystyrene dosage increases, a behavior that demonstrates the more advanced 
degradation of polyisoprene component compared to the polystyrene one, the two polymers degradation being independent, without an interference between the destruction mechanism [32, 33].

The total degradation of SIS block-copolymers and its composite is achieved in the range of $403-550^{\circ} \mathrm{C}$, the polystyrene phase having a more important contribution at the residue increased as can be observed in table 3 .

From data showed in tables 2 and 3 it can be noticed that the thermal degradation effect of block-copolymers and their polystyrene composites is manifested most strongly in the temperature range of $300-550^{\circ} \mathrm{C}$. The graphical representation of temperature-related weight loss in this range allows us to observe more clearly the different behavior of the composite degradation of the two block copolymers (fig. 12 and 13).

Considering as reference polystyrene degradation it can be noticed thatSBS block copolymers and their composites exhibit a superior degradation resistance (fig. 12) while SIS block-copolymers and composites show an inferior thermal stability (fig. 13). Increasing the polystyrene dosage decreases the thermal stability of SBS blockcopolymers but has an opposite effect at SIS blockcopolymer composite.

Following the thermal behavior analysis, itcan assumed that SBS block-copolymer and its composites exhibit a superior thermal stability compared to virgin polystyrene and SIS block copolymers and its associated composites.

\section{Conclusions}

The study established that reinforcing the styrene-diene and isoprene block-copolymers with polystyrene by centrifugal casting from toluene solution leads to the obtaining of composites with performant properties due to the filler uniform distribution into the polydiene phase.

The SBS block-copolymer showed a superior thermal stability to the SIS block-copolymer a feature that also is maintained in the case of their composites with polystyrene.

Acknowledgment: This work was funded by the Romanian Ministry of Research and Innovation through theProgram Nucleu PN.18.22.04.02 OXOBIOPOL.

\section{References}

1.BUTHANIA A. I., KARRER M.K., Int. J. Eng. \& Technol.,12 (3), 2012, p. 19.

2.HOLDAN G., Thermoplastic Elastomers in Applied Plastics Engineering Handbook: Processing and Materials, Elsevier, Oxford, UK, 2011, p. 77.

3.ASO 0., EGUIZABAL J .I., NAZABAL J ., Compos. Sci. Technol., 63 (3), 2007, p. 2854.

4.UTRACKI L.A., WILKIE C.A., Polymers Blends Handbook, Springer, 2014.

5.GHEORGHE, V., FETECAU, C., AMARANDEI, D., SERBAN, A., Experimental Research on The Milling Process of Some Composite Materials, Mat. Plast., 53, no. 1, 2016, p.157

6.KENT J.A, Handbook of Industrial Chemistry and Biotechnology, Springer N.Y 2012, p. 638.

7.SATAPATHY B. K., LACH R., WEIDISCH R., SCHNEIDET K., JANKE A., KNOLL K., Eng. Fract. Mech., 73 (16), 2006, p. 2399.
8.HOLDEN G., New Developments in Block Copolymer Applications, in RecentAdvances in Polymer Blends, Grafts and Block from Polymer Science and Technology, vol. 4, Edited Sperling L.H., Plenum Press, Ed. 4, 2014, p. 274.

9.HOLDEN G., LEGGE N.G., QUIRK, R.P., SCHRODERE H.E., Thermoplastic Elastomers, Hanser Publisher, Vienna, 2006.

10.HSIEH H.L., QUIRK R.P., Anionic Polymerization, Marcel Dekker, NY, 2008.

11.HADYICHRISTIDIS N., HIRAO A., Anionic Polymerization. Principles, Practice, Strength, Consequences and Applications, Springer, Japan, 2015.

12.DANESHFAR Z., GOHARPEY F., J. Polym. Res. 23 (8), 2016, p. 1.

13.DUAN Y., THUNGA M., SCHLEGEL R., SCHNEIDER K., RETTLER E., WEIDISGH R., SISLER H.W., STAMM M., MAYS J.W., HASYICHRISTIDIS N., Macromolecules 42 (2), 2009, p. 4155.

14.ADHIKARI R., DAMM C., MICHLER G.H., MUNSTEDT H., BALTACALLEJA F.J ., Compos. Interface 15 (5), 2008, p. 453.

15. GHIOCA P., IANCU L., VULUGA Z., SPURCACIU B., GRIGORESCU R., IORGA M., FLOREA D., Mat. Plast., 53, no. 1, 2016, p. 34.

16.GHIOCA P., IANCU L., GRIGORESCU R. M., SPURCACIU B., NICOLAE C. A. GABOR A. R., , Mat. Plast., 54, no. 3, 2013, p. 481

17.HASHIMOTO T., TANAKA H., HASEGAWA H., Macromolecules 23 (20), 1990, p. 4378.

18.KOIZUMI S., HASEGAWA H., HASHIMOTO T., Macromolecules 27, 1994, p. 7893.

19.ZHAO S.Y., CHEN F., FU Q., Polym. Sci. 33 (7), 2015, p. 964.

20.KOIZUMI S., HASEGAWA H., HASHIMOTO T., Macromol. Chem. Symp. 62,1992, p. 75.

21.KOIZUMI S., HASEGAWA H., HASHIMOTO T., Macromolecules 27, 1994, p. 6532.

22.HASEGAWA H., HASHIMOTO T., Comprehensine Polymer Science Suppl 2, Pergamon, London, 1996, p. 497.

23.WUNSCH J. R., Polystyrene: Synthesis, Production and Application, Rapra Technology, 2000, p. 26.

24.LEE K.Y., PAUL D.R., Polymer 46, 2005, p. 9064.

25.SEN S., THOMAS J . D., KUMAR S.K., KEBLINSKI P., Macromolecules, 40, 2007, p. 4059.

26.MESSORI M., in Recent Advances in Elastomeric Nanocomposites, Advances Structured Materials, edited by Mittal V, et. all, SpringerVerlag, 2011, p. 57.

27.HACALOGLU J., ERSEN T., ERTUGRUL N., FARES M., SUZER S., Eur. Polym. J. 33 (2), 1997, p. 199.

28.VISAKH P.M., ARO Y., Thermal Degradation of Polymers, Blends, Composites and Nanocomposites: Springer Switzerland, 2015.

29.LUDA M.P., GUAITA M., CHIANTORE O., Macromolecular Chemistry and Physics, 193 (1), 1992, p. 113.

30.RYBINSKI P., KUCHARSKA-J ASTRZABEK A., JANOWSKA G., Polymer Science, Series B, 56 (4), 2014, p. 477.

31.KUTZ M., Handbook of Environmental Degradation of Materials (Second Edition) Elsevier, U.K., 2012.

32.HACALOGLU, J., FARES, M., SUZER, S., Eur. Polym. J., 35, 1999, p. 939.

33.GHIOCA, P., IANCU, L., SPURCACIU, B., GRIGORESCU, R. M., GABOR

A. R., NICOLAE, C. A., Mat. Plast., 50, no. 3, 2013, p. 188.

34.GONON L, GARDETTE J L, Polymer, 41, 2000, p. 1669.

35.DECKER C, ZAHOILY K, DECKER D, NGUYEN T, VIET T, Polymer, 42, 2001, p. 7551.

Manuscript received: 27.09.2017 